\title{
Older patients' experiences during care transition
}

\author{
Else Cathrine Rustad ${ }^{1-4}$ \\ Bodil Furnes' \\ Berit Seiger Cronfalk ${ }^{2,5,6}$ \\ Elin Dysvik' \\ 'Department of Health Studies, \\ Faculty of Social Sciences, University \\ of Stavanger, Stavanger, Norway; \\ ${ }^{2}$ Faculty of Health and Caring \\ Sciences, Stord Haugesund University \\ College, Stord, Norway; ${ }^{3}$ Research \\ Network on Integrated Health \\ Care in Western Norway, Helse \\ Fonna Local Health Authority, \\ Haugesund, Norway; ${ }^{4}$ Department \\ of Clinical Medicine, Helse Fonna \\ Local Health Authority, Haugesund, \\ Norway; ${ }^{5}$ Palliative Research Center, \\ Ersta Sköndal University College, \\ Stockholm, Sweden; ${ }^{6}$ Department \\ of Neurobiology, Care Sciences \\ and Society, Karolinska Institutet, \\ Stockholm, Sweden
}

This article was published in the following Dove Press journal:

Patient Preference and Adherence

12 May 2016

Number of times this article has been viewed

Background: A fragmented health care system leads to an increased demand for continuity of care across health care levels. Research indicates age-related differences during care transition, with the oldest patients having experiences and needs that differ from those of other patients. To meet the older patients' needs and preferences during care transition, professionals must understand their experiences.

Objective: The purpose of the study was to explore how patients $\geq 80$ years of age experienced the care transition from hospital to municipal health care services.

Methods: The study has a descriptive, explorative design, using semistructured interviews. Fourteen patients aged $\geq 80$ participated in the study. Qualitative content analysis was used to describe the individuals' experiences during care transition.

Results: Two complementary themes emerged during the analysis: "Participation depends on being invited to plan the care transition" and "Managing continuity of care represents a complex and challenging process".

Discussion: Lack of participation, insufficient information, and vague responsibilities among staff during care transition seemed to limit the continuity of care. The patients are the vulnerable part of the care transition process, although they possess important resources, which illustrate the importance of making their voice heard. Older patients are therefore likely to benefit from more intensive support. A tailored, patient-centered follow-up of each patient is suggested to ensure that patient preferences and continuity of care to adhere to the new situation.

Keywords: care transition, older patients, continuity of care, participation, communication

\section{Introduction}

People $\geq 80$ years of age constitute the fastest growing age group in the western world. In addition to general age-related functional impairment, older people are at increased risk of diseases such as dementia, cancer, and cardiovascular diseases. ${ }^{1}$ In the current health care system, several health care providers, with different financial systems and areas of competence, are offering acute and long-term treatment and care. ${ }^{2,3}$ The complexity of the cooperation between different health care levels makes the process of moving across these levels challenging. ${ }^{4,5}$ Care transition is understood as the continuity of health care when the patient is transferred across different health care levels. ${ }^{3}$ Older people are large consumers of health care services, which leave them vulnerable to adverse incidents and make them a target for alterations to reduce medical costs. ${ }^{6-9}$ To meet the needs and preferences of older patients better, research has altered focus from a health-administrative perspective on care transition to the patients' experiences of the continuity of care during care transition. ${ }^{10,11}$ Theories such as person-centered care, based on values of mutual respect, self-determination, and understanding, have been widely acknowledged. ${ }^{12}$ A successful care transition of older patients, across health care levels, forms the basis of well functioning and continuous residential treatment and care..$^{3,13}$
Correspondence: Else Cathrine Rustad Stord/Haugesund University College, Klingenbergvegen 8, N-54I4 Stord, Norway Email else.rustad@hsh.no (c) (1) (5) 2016 Rustad et al. This work is published and licensed by Dove Medical Press Limited. The full terms of this license are available at https://www.dovepress.com/terms.php
and incorporate the Creative Commons Attribution - Non Commercial (unported, v3.0) License (http://creativecommons.org/licenses/by-nc/3.0/). By accessing the work you (c)
hereby accept the Terms. Non-commercial uses of the work are permitted without any further permission from Dove Medical Press Limited, provided the work is properly attributed. For permission for commercial use of this work, please see paragraphs 4.2 and 5 of our Terms (https://www.dovepress.com/terms.php).
s. 
In Norway, as in many other western countries, the health care system is organized vertically in two sectors; primary health care, run by the municipalities, are responsible for nursing homes, home care and general practitioners, while the hospital sector is run by the national health authorities. ${ }^{14}$ The Norwegian Government proposed The Coordination Reform, to be gradually implemented. ${ }^{15}$ The reform aimed at improving coordination across health care levels, and the patient's experience of continuity of care, through increased treatment and care of patients at primary care level and earlier discharge from hospitals and specialist care. The strategies of the Norwegian reforms are comparable to reforms in other Scandinavian countries. ${ }^{14}$ Evaluations indicate that The Coordination Reform has unintentionally led to an increase in care transitions, as primary care more often receives sicker patients, leading to readmissions in hospital, and the reform seems to have led to a fragmented health care service for the older patient. ${ }^{16-18}$ Based on this, there is an urgent need to explore the present situation more closely from the older patients' perspective, looking for actions and improvements.

The older generation themselves tend to meet their situation with an attitude of acceptance and a denigration of their own needs, which masks their vulnerability in the care-transition process. ${ }^{19,20}$ Notwithstanding, recent research suggests that there should be more focus on age-related differences among older patients during care transition. Bobay et $\mathrm{al}^{21}$ found no association between discharge preparation and discharge readiness among patients $\geq 85$ years of age. The oldest patients reported being given less information than elder patients $\geq 65$ years of age. Further, Allen et $\mathrm{al}^{22}$ show how lack of communication systems across health care levels negatively affects older patients care transition, indicating the importance of proper information not only between multiprofessional health carers but also to the older patient. In a large study by Holland et al, ${ }^{23}$ a considerable amount of unmet needs after discharge of patients from hospital to home and self-care was identified. An incongruence was found between health care staff's impression of the patient's capacity and what they actually were capable of performing, and the patient was often dependent on informal assistance to cope immediately after discharge. As such, the challenge to create a safe environment that meets the expectations and needs of the oldest old patients across health care levels still remains.

Given these considerations, the aim of this study was to explore how patients $\geq 80$ years of age experience the care transition from hospital to municipal health care services. To identify various aspects of the care-transition process, the following research questions were formulated: How do older patients experience participation in planning the care transition from hospital to municipal health care? How do older patients experience continuity in treatment and care during care transition from hospital to municipal health care?

\section{Methods}

The present study used a qualitative approach with a descriptive and explorative design. Individual and semistructured interviews were conducted with 14 participants. Content analysis of the interviews was performed to capture the individual's experiences during the care transition. ${ }^{24}$

\section{Sampling and participants}

Older patients $\geq 80$ years of age were recruited from a local hospital in Norway. Registered nurses selected the participants using the following inclusion criteria: $\geq 80$ years and admitted to medical, surgical, or geriatric wards with a planned discharge to municipal health care services.

Eighteen patients (eleven women and seven men, aged 81-94 years) with various diagnoses, such as cancer, stroke, and pneumonia, agreed to participate. Four patients (two women and two men) later withdrew from the study because of deteriorating health after being discharged from hospital. Background data, including the participants' different transitions across the health care levels and to different health care providers, are described in Table 1.

\section{Interviews}

All interviews were conducted by the first author (ECR). The participants were contacted (ECR) by telephone 1-2 weeks after discharge from hospital to schedule an appointment for the interview. The interviews were semistructured, with open questions (as described in Supplementary material 1) and lasted for 27-96 minutes. The participants were given the opportunity to speak freely about their experiences, and their stories and statements directed the conversation. However, an interview guide ensured that the main topics were addressed (Supplementary material 1). Three participants were interviewed at a nursing home where they had a short-term stay, and eleven participants were interviewed in their own home or at a residential service apartment. Two of the interviews were conducted in the presence of family at the participants' request, for convenience and because of hearing impairment. The participants agreed to have the interviews tape recorded.

\section{Data analysis}

The interviews were transcribed verbatim and analyzed using qualitative content analysis inspired by Graneheim and 
Table I Background data of participants, $n=14$

\begin{tabular}{|c|c|c|c|}
\hline Patient & Age (years) & $\begin{array}{l}\text { Cause for admission } \\
\text { to hospital }\end{array}$ & Care transition \\
\hline Female & 87 & Unknown to the patient ${ }^{\mathrm{a}}$ & Home - hospital - home \\
\hline Female & 89 & Unknown to the patient ${ }^{\mathrm{b}}$ & Home - hospital - nursing home - home \\
\hline Female & 87 & Fall & Home - hospital - home \\
\hline Male & 88 & Fall & Home - hospital - home \\
\hline Female & 89 & Fall & Home - hospital - home \\
\hline Male & 86 & $\begin{array}{l}\text { Only the primary diagnosis } \\
\text { known to the patient }{ }^{c}\end{array}$ & $\begin{array}{l}\text { Home - hospital - rehabilitation at the nursing } \\
\text { home - hospital - nursing home - home }\end{array}$ \\
\hline Female & 94 & Infection & Home - hospital - home \\
\hline Female & 81 & Paralyzed bowel & Home - hospital - home \\
\hline Female & 84 & Wrong medication & Service apartment - hospital - service apartment \\
\hline Female & 92 & Cancer & $\begin{array}{l}\text { Service apartment - hospital - service apartment - } \\
\text { hospital - service apartment }\end{array}$ \\
\hline Male & 87 & Infection & Home - hospital - home \\
\hline Female & 90 & Stroke & Service apartment - hospital - nursing home \\
\hline Male & 91 & Stroke & Home - hospital - home \\
\hline Male & 88 & Pneumonia & Home - hospital - home \\
\hline
\end{tabular}

Notes: a Reduced general condition, ${ }^{b}$ fall, ${ }^{c}$ complications following elective surgery, pneumonia, heart attack, and reduced general condition.

Lundman, ${ }^{24}$ through the following steps: the interviews were transcribed verbatim. The transcriptions were read through several times to gain a sense of the whole. Meaning units were then identified and extracted from the transcriptions and further condensed, ensuring that the meaning was maintained while shortening the text. The condensed meaning units were labeled, and based on their similarities, coded for further assortment. The codes were sorted based on their similarities into categories to preserve the diversity of the participants' experiences. To ensure the diversity of the content, the analysis (presented in Table 2) includes subthemes in addition to the overall theme. The analysis was guided by the research questions to ensure that the participants' experiences during care transition were captured. Data analysis was an active process, going back and forth between different steps of the analysis. In cases of any ambiguity, the transcribed text or audiotape was used to clarify the participant's expression. Each author performed the analysis independently, and the findings were discussed until agreement was reached.

\section{Ethics}

The study was approved by the Regional Committees for Medical and Health Research Ethics (Project number 2010/3342) and was reported to Norwegian Social Science Data Services. Based on instructions, an registered nurse at each ward provided information about the study, both verbally and in writing. Participants were assured anonymity and confidentiality and informed that they could withdraw from participation in the study at any time without any consequences for treatment and care. Participants signed a

Table 2 Examples of the abstraction process of the content analysis, $n=14$

\begin{tabular}{|c|c|c|}
\hline Category & Subtheme & Theme \\
\hline Was asked to participate in discharge meeting & $\begin{array}{l}\text { Formal and informal participation in planning } \\
\text { the care transition }\end{array}$ & $\begin{array}{l}\text { Participation depends on being invited } \\
\text { to planning the care transition }\end{array}$ \\
\hline \multicolumn{3}{|l|}{ Was asked their opinion about future care needs } \\
\hline The family helped in planning the care transition & $\begin{array}{l}\text { Partial participation in planning the care } \\
\text { transition }\end{array}$ & \\
\hline $\begin{array}{l}\text { Don't remember being asked to participate in } \\
\text { planning the care transition } \\
\text { Was not asked to participate in planning care } \\
\text { transition }\end{array}$ & No participation in planning the care transition & \\
\hline $\begin{array}{l}\text { Information from hospital to home-care staff and } \\
\text { patient }\end{array}$ & $\begin{array}{l}\text { Communication during care transition takes } \\
\text { place on different levels }\end{array}$ & $\begin{array}{l}\text { Managing continuity in care represents } \\
\text { a complex and challenging process }\end{array}$ \\
\hline \multicolumn{3}{|l|}{ Experiences with written documentation } \\
\hline \multicolumn{3}{|l|}{ Communication from patient to health care staff } \\
\hline Unresolved responsibility & Responsibility during care transition varies & \\
\hline \multicolumn{3}{|l|}{ Handing over the responsibility } \\
\hline \multicolumn{3}{|l|}{ Obliged responsibility } \\
\hline Personal responsibility & & \\
\hline
\end{tabular}


written informed consent form before contact information was given to the first author.

\section{Findings}

The data comprised extensive and detailed descriptions of the participants' experiences during care transition from hospital to municipal health care. Our findings represent both similarities and diversities in the participants' experiences. The main findings were developed and formulated in two complementary themes. The theme "Participation depends on being invited to plan the care transition" encompassed the subthemes of "Formal and informal participation in planning the care transition", "Partial participation in planning the care transition", and "No participation in planning the care transition". The second theme formulated was "Managing continuity in care represents a complex and challenging process", abstracted from the subthemes: "Communication during care transition takes place on different levels" and "Responsibility during care transition varies". Examples of the abstraction process of the content analysis are presented in Table 2. The results will now be presented, with selected quotations from the participants used to illustrate each subtheme and allow the reader to assess the evidence directly.

\section{Participation depends on being invited to plan the care transition}

Hardly any participant described taking part in organized formal meetings to plan their future care needs. Examples of abstraction process of participation when planning the care transition are presented in Table 3.

One older patient was invited to participate at an interdisciplinary meeting, and the patient's family was asked to join in the discharge meeting. The patient seemed well prepared and mentioned several questions that he wanted to ask if given the opportunity.

Table 3 Examples of abstraction process of participation when planning the care transition, $n=\mid 4$

\begin{tabular}{lll}
\hline Theme & Category & Subtheme \\
\hline Participation depends on being & Was asked to participate in & Formal and informal \\
invited to planning the care & discharge meeting & participation in planning the \\
transition & & care transition
\end{tabular}

\begin{abstract}
Condensed meaning unit
There is supposed to be a final meeting here before I go home. The staff will recommend the home services that I will need when I am discharged. And if we want something we can let them know tomorrow at the meeting.

I could have home care for as long as I felt I needed it, and it has not ended yet.
\end{abstract}

about future care needs

I think I was asked several questions about my needs of care when I was discharged.
The family helped in planning the care transition

Partial participation in planning the care transition

No participation in planning the care transition

I wasn't asked if I wanted to be discharged home to my apartment when I was at the hospital. I believe it was my daughters who applied for the nursing home.

With me, they only discussed more general stuff, but I said that I have my wife at home, and she can help me with almost everything.

Don't remember being asked to participate in planning the care transition

Was not asked to participate in planning care transition
I can't remember that I was asked in hospital about what help I would need at home after discharge. I told them that I was alone. And all the aids were already in my apartment when I arrived at home.

I was probably asked about my home situation at the hospital, but I don't remember now. And I don't remember my answer either.

I knew there was no reason for me to stay there any longer. I can't remember being asked about the discharge and home care.

I don't remember that I was asked directly about what I wanted, but they didn't do anything against my will. 
There is going to be a meeting here before I'm discharged (from a short-term municipal institution). They will recommend for home service the things that I need. And if we want something, we could let them know tomorrow at the meeting. And both my wife and my son will participate, and probably the nurses who has cared for me.

However, the most common experience when planning the care transition was the informal "bedside" question about the participants' health care preferences after being discharged.

The nurses asked me if I wanted to be transferred to the nursing home, but I didn't believe that it was necessary.

Some of the participants believed that their family was involved in the process and had communicated with the health care staff. This was experienced differently; for some participants, not having to deal with planning the discharge seemed to be a relief, whereas others perceived it negatively and had been left feeling dissatisfied.

No, I wouldn't know because I didn't have anything to do with that. It is the girls who have arranged it. They don't believe I could manage anything any longer. But it is okay, I put up with it.

A few participants reported that they could not recall any influence on the care transition at all. One participant was not sure when he was to be discharged but guessed that he was supposed to leave hospital because his physical condition had improved.

I didn't take part in the discussion about my care needs. I don't remember that I was asked directly about what I wanted, but they didn't do anything against my will, that's for certain.

Thus, not being invited to participate in planning the care transition was not explained as a totally negative experience.

\section{Managing continuity of care represents a complex and challenging process}

The participants described the care transition from hospital to municipal health care as a complex experience comprising many elements. Examples of abstraction process of patient experiences during care transition are presented in Table 4 .

All of the participants described experiences related to information and communication during their interviews, and the statements reflect the multitude of communication channels that the participants faced during care transition.
Several of the participants mentioned the communication between hospital staff and home-care staff in their interviews. A few participants expressed confusion about not knowing what information had been sent from the hospital and received by the municipal health care staff.

I've been receiving a new kind of medication since I was in hospital. I don't know if it is because of directions from the hospital or [...] I just take them and keep quiet (...).

A few of the participants commented on the written documentation they were given when discharged. The participants expressed insecurity about their obligations in relation to the documents and frustration because the written terminology was difficult to understand. At risk of not receiving the help he needed, one participant made a real effort to ensure that the written information about his medical condition reached the municipal home-care office.

I received a letter from the hospital addressed to the municipal health care services with no stamps on it. So, I had to take my walker and walk to the kiosk down the street to buy a stamp and post the letter to the municipal health care services. I don't want to say anything but I have my own opinion about that.

Almost all of the participants felt secure knowing that they were going to be well looked after by the health care providers and their general practitioner.

Yes, I felt safe when leaving the hospital. I knew that I had my general practitioner next to where I live, and I also have a safety alarm.

Several of the participants talked about how they could contact the home-care staff if needed, by using a safety alarm or by talking to the nurses who visited them daily. Some participants possessed informal lines of communication to feel secure, as exemplified in next quotation.

If my general practitioner couldn't help me, I know the chief of home care. She used to work in my store, so she could probably take care of most things. And also my grandson's wife is a home-care nurse. It is not a problem for me to get in contact with the right person if I need to.

All of the participants described several views of responsibilities during care transition, and some of the older patients described handing over the responsibility as a positive experience. One of the participants felt relieved.

But it has worked out. I get my medication delivered now, so I am, so to speak, free from it all. 
Table 4 Examples of abstraction process of patient experiences during care transition, $n=14$

\begin{tabular}{lll}
\hline Theme & Category & Subtheme \\
\hline Managing continuity in & Information from & Communication during \\
care represents a complex & hospital to home- & care transition takes \\
and challenging process & care staff and patient & place on different levels
\end{tabular}

Condensed meaning unit

Yes, they had contact, so everything worked just fine. The hospital told the municipal home care, who said that they would come in the evening.

At the same time as we came home, we called the nurse from home care who took the papers I was given at the hospital. They had called from hospital as well, but I don't know what they said.

Experiences with written documentation

Communication from patient to health care staff

Unresolved responsibility

Handing over the responsibility

Obliged responsibility

Personal

responsibilities
Someone gave me a piece of paper and, I suppose, no [...] I guess I should just keep it. I don't think I should even deliver it.

I don't receive enough help. I have a letter from the municipal home-care service, but I can't sign that I am satisfied with their services. l'll just leave it until they send a reminder, and then I get to tell them what I think about the aid they are not providing.

I've been receiving a new kind of tablet since I was in hospital. I don't know if it is because of directions from the hospital, I just take them and keep quiet.

If I need more help, I just contact the home-care office because I can get more help if needed.

Responsibility during care transition varies

There is a nurse from home care saying that she is my primary contact. I didn't catch her name, but that doesn't matter. Then, I at least know that someone is responsible for me.

I don't know if I am taking too much medicine because there is no one in charge of that now. I believe I have to go to my general practitioner to give a blood sample, but nobody has told me to do that.

$\mathrm{He}$ (his son) has taken care of it all from the beginning. He called the Municipal Decision Office and made sure that they came from the municipal health care.

A safety alarm has been applied for, but it is a long wait. This was applied for when I was still in hospital.

And then I thought I should call the municipal home care and check with them. I think that gradually I will be able to manage on my own.

You don't open the book of law to read all these paragraphs. And you don't go to the municipal homecare office either to ask what it means. So, I don't think many people would make a complaint about the resolutions. This is simply just a waste of paper.

I started to use a walking stick today, and I stopped using the walker. I will start to exercise. You know, I got tired really fast, but I can't give up.

In the hospital, the physiotherapist gave me an exercise description, and I have used it all by myself as much as I have been able to. So, my condition has improved a lot, from sitting in a wheelchair to using a walking stick. 
Other participants described how they tried to withhold responsibility for their own situation themselves, expressing optimism about their ability to be in charge of their own situation.

I will at least try to go home because if it doesn't work out,

I can apply for a short-term stay here at the nursing home.

I really think that's what's best for me.

Almost all of the interviewees noted that they made a huge effort to take personal responsibility for their own health and rehabilitation.

At hospital, I was working out by walking up and down the stairs, holding heavy things in my hands. And I walked in the parallel bars. I exercised every day as much as I could manage, just to improve my mobility, and I recovered. I got help from the physiotherapist and the occupational therapist. And I noticed that the power and mobility in my left arm and foot improved.

The participants described responsibilities ranging from physical rehabilitation to being responsible for their own medication in accordance with their perceived functional abilities.

\section{Discussion}

The aim of this study was to explore how people $\geq 80$ years of age experienced the transition from hospital to municipal health care services. Two complementary themes, which greatly affected the older patient's experiences during care transition, were developed through the analysis: "Participation depends on being invited to plan the care transition" and "Managing continuity in care represents a complex and challenging process". The discussion was arranged according to these themes to highlight different aspects of the care transition process of older patients.

\section{Participation depends on being invited to plan the care transition}

In our study, only one participant experienced formal participation, being invited to take part in a discharge meeting. The participant felt well-informed about who would attend the meeting and what questions and problems he could address. This is in agreement with the findings by Bångsbo et $\mathrm{al},{ }^{25}$ who indicate that patient participation is affected by the patient's level of preparation. However, the actual influence that older patients may exercise in such discharge meetings might be limited by the professionals' perception of opportunities for postdischarge arrangements. ${ }^{26,27}$
Most of the older patients in our study experienced a more informal bedside approach, being asked about their preferences after discharge. Previously, older patients' preference about being actively involved in decision making was questioned. ${ }^{28-30}$ However, more recent research argues that older patients do want to participate in decision making about their care transition, but because of the inequity in power between the patient and the professionals, the patients are left in a vulnerable position and may therefore be reluctant to communicate their preferences. ${ }^{31-34}$ This might explain our finding that patients were waiting to be asked for their opinions instead of taking an active approach to participating in planning their care transition. Some of our participants indicated that the family took part in planning the care transition. A few of them did not totally agree with their family even though they accepted the decisions made on their behalf. Extended support from either family or professionals has been shown to facilitate patient participation and give older patients a stronger position from which to influence the decisions. ${ }^{32,35,36}$

In our study, some patients described that they could not recall any participation at all. Some of them made firm statements that they were not asked for their opinion at all when planning the care transition. Horwitz et $\mathrm{al}^{37}$ found that onethird of the older patients were given less than a day's notice in advance of the discharge. In addition to the professionals spending limited time with the patient, the opportunities for proper patient participation in the discharge planning might be reduced..$^{37,38}$ One of the patients in our study expressed that the nurses did not do anything against his will. As such, our findings might also illustrate the complexities of patient participation due to relational elements, which may impede the possibilities for participation. Similarly, Foss ${ }^{34}$ found that older patients identified themselves with a cultural understanding of age as being old and slow. As such, older patients took responsibility for the lack of participation, which reflects the tensions surrounding the conflicting holistic needs of the patient and the hospital. ${ }^{34}$

Our findings can also be understood by characteristics specific to older people in general, as individuals of this generation often have lifelong experience of a paternalistic health care system. ${ }^{31}$ In addition, older patients seem to experience feelings of powerlessness, lack of knowledge, and being disempowered and pacified. ${ }^{31,32,39,40}$ These circumstances contrast with proactive involvement in the process of planning the care transition from hospital to home. As such, the minimal participation found in our study might 
be interpreted as influenced by the attitudes of the professionals in a health care system practice where participation is not properly established. ${ }^{17,33,38}$ However, like our findings indicate, Bynum et $\mathrm{al}^{32}$ found that some barriers to participation, such as lack of communication during medical decisions for older patients, can be modifiable, although this research needs further attention.

Because our findings varied from formal and informal participation to no participation, we suggest that professionals must take the initiative to invite and facilitate older patients' participation in the planning of care transition. More focus on older patient's values and right to self-determination are emphasized to minimize the identified deficits.

\section{Managing continuity in care represents a complex and challenging process}

All the older patients in this study had experiences with communication and information exchange. The findings show that some participants described being well informed while others were worried because of lack of understanding of the information. We interpret our findings as pointing out two important elements of the older patients' experiences during care transition. Without confirmation that the information has been communicated across the health care levels, older patients are left to trust that the home-care nurse is informed about their homecoming and is given enough detailed information to maintain the continuity of the hospital care. Similar to our findings, several studies report a lack of information continuity across health care levels, and lack of information exchange has proven to compromise patient safety. ${ }^{8,22,41-43}$ Communication skills, in terms of speaking directly to the patient, or "above the patients head", have been shown to affect participation negatively in discharge meetings. ${ }^{25}$ As such, our findings might indicate that older patients experience a lack of control and feel unsafe when they are talked about but do not know what is being said.

Some of the older patients in our study explained that the written summary of their treatment and care was difficult to understand and they expressed uncertainty about its intentions. Two of the participants could not remember their diagnosis and did not understand why they were admitted to hospital. Previously, health care literacy, mild cognitive impairment, and not being given a thorough explanation in words that they can understand are identified as barriers to older patient's understanding of their own treatment and care during care transition..$^{39,44,45}$

Most of our participants stated that they could contact a health care provider if necessary, using several different channels of communication. Knowledge of whom to contact if necessary has been described as an important part of older patient's satisfaction with quality of care. ${ }^{46}$ As identified in our data, the lines of communication in the health care system are complex and difficult to navigate, involving older patients and their family, the general practitioner, and health care staff on both health care levels. Clearly, there is a need to establish a communicative relationship with older patients, allowing them to bring forth their questions and worries in a safe environment.

Our findings indicate that allocation of responsibility could be experienced in several ways. This might reflect a health care system often experienced as fragmented, with ambiguous areas of responsibility that fail to meet older people's expectations and needs. Like in our study, Altfeld et a ${ }^{47}$ found that a majority of the informants reported altered and new needs emerging shortly after discharge, which might explain contribution to the older patients' experience of insecurity regarding responsibilities.

A different kind of responsibility is seen in the participants' expressions about their own efforts to regain health and be actively involved. These efforts were directed by their physical strength and their perceived abilities to face the challenges that they experienced. Such personal values and self-efficacy are shown to be important resources for older patients for maintaining responsibility for their own rehabilitation after discharge, but they seem to be overlooked. ${ }^{48}$

The clarification of information and responsibilities is identified as different but important experiences in the transition from hospital to municipal health care. These aspects may also be seen as intertwined because insufficient information seems to limit the older patient's understanding and feelings of being properly taken care of. On the other hand, the notion of being taken care of is of less value if one does not possess the information of how to get in touch with the right health care worker when needed. These findings could also be seen as a partial explanation of why older patients participate to a limited extent in planning their care transition. Obviously, to secure continuity of care, the communicative relationship with older patients as well as between health care staff across health care levels must be improved. This in turn would lead to better information flow, and hopefully the voice and resources of the older patient will be more in focus.

\section{Methodological considerations}

The strength of our study is that 14 older people with various health problems provided extensive descriptions of the phenomena of the study. The sex imbalance in the present 
study mirrors the sex distribution in the older population in Norway, where women tend to live longer than men. ${ }^{49}$ Several steps were taken to ensure the credibility of the study. The interview guide was pretested by one older person who was not included in the study. Judgments were made about follow-up questions and when to end the data collection. Transparency was sought through distinct descriptions of the analytical steps and presentation of quotations. The similarities and differences in the content that surfaced during the interview process were discussed within the research team. Each author carried out the analyses independently, followed by a shared process to reach consensus. As such, our interpretation highlights the most probable meaning of care transitions from a particular perspective. We suggest that our findings may be transferable to other professionals or people in similar situations by considering the culture and context, as well as methods of data collection and analysis.

\section{Implications for practice}

The findings of this study suggest important implications for the formation of the patients' rights and opportunities for participation. Well in advance of their discharge from hospital, older patients should be invited to share their opinions and concerns about the care transition. To secure continuity of care, they should be given the necessary information to be able to participate in planning the care transition in accordance with their preferences. Moreover, throughout the hospital stay and the transition to municipal health care, older patients should be kept thoroughly informed about all the initiatives and communications made on their behalf. The professionals who are responsible during the transition should be referred to by name so that older patients receive legitimate confirmation of who is responsible for them and the continuity of their care. In addition, older patients should know whom to contact and who is responsible for their care. It is important to map the patients' prerequisites in order to tailor the care individually. Continuously mapping older patient's needs and preferences in the first weeks after discharge will enable the accommodation of challenges not foreseen before discharge from hospital. Our approach might also create a basis for improving care transition for cognitively impaired patients.

\section{Conclusion}

Our study identified various aspects of the care transition process, and our findings clearly indicate that it is a complex process with many challenges for, and requirements of, older patients, professionals, and the health care system. To secure continuity of care, a specific focus should be directed toward older patient's participation in planning care transition, how communication and responsibilities can be organized to formulate better policies, and the development of better practice in serving older patients. Older patients are the vulnerable part in the transition process, and it is important to make their voices heard and equip professionals with the necessary insight to meet their needs best and secure continuity of care. Further research is needed to achieve more detailed knowledge about older patient's worries and preferences during this important period of their treatment and care to adhere to their new situation.

\section{Acknowledgments}

The authors would like to thank leaders and staff of a local institution for giving access to the field. We extend our sincere gratitude to the 14 patients who voluntarily participated in this study. This study has been supported by a grant from The Western Norway Regional Health Authority (911672), Stord/ Haugesund University College and the Research Network on Integrated Health Care in Western Norway.

\section{Disclosure}

The authors report no conflicts of interest in this work.

\section{References}

1. Christensen K, Doblhammer G, Rau R, Vaupel J. Ageing populations: the challenges ahead. Lancet. 2009;374(9696):1196-1208.

2. Boeckxstaens P, De Graaf P. Primary care and care for older persons: position paper for The European Forum for Primary Care. Qual Prim Care. 2011;19(6):369-389.

3. Coleman EA. Falling through the cracks: challenges avand opportunities for improving transitional care for persons with continuous complex care needs. J Am Geriatr Soc. 2003;51(4):549-555.

4. Drury LJ, Billings D, Kowalski K. Transition from hospital to home care: what gets lost between the discharge plan and the real world? $J$ Contin Educ Nurs. 2008;39(5):198-199.

5. Popejoy LL, Moylan K, Galambos C. A review of discharge planning research of older adults 1990-2008. West J Nurs Res. 2009;31(7): 939-947.

6. Statistics Norway. Eldres bruk av helse og omsorgstjenester/Health and Care [Use of Health Care Services among the Elderly]. Oslo, Norway: Statistics Norway; 2013. Norwegian. Available from: http:// www.ssb.no/helse/artikler-og-publikasjoner/_attachment/125965? ts=13f8b5b6898. Accessed November 20, 2014.

7. Clegg A, Young J, Iliffe S, Rikkert M, Rockwood K. Frailty in elderly people. Lancet. 2013;381:752-762.

8. Mesteig M, Helbostad JL, Sletvold O, Røsstad T, Saltvedt I. Unwanted incidents during transition of geriatric patients from hospital to home: a prospective observational study. BMC Health Serv Res. 2010;10:1.

9. Arbaje AI, Boonyasai, Romsai T, Dilworth-Anderson P. The older person in transition. implications for pathways of transitions of care. Annu Rev Gerontol Geriatr. 2011;31(1):15-30.

10. Gulliford M, Naithani S, Morgan M. What is "continuity of care?" $J$ Health Serv Res Policy. 2006;11(4):248-250. 
11. Shepperd S, Lannin NA, Clemson LM, McCluskey A, Cameron ID, Barras SL. Discharge planning from hospital to home. Cochrane Database Syst Rev. 2013;1:CD000313.

12. McCormack B, McCance T. Person-Centred Nursing. Theory and Practice. 1st ed. Chichester, UK: Wiley-Blackwell; 2010.

13. Bauer M, Fitzgerald L, Haesler E, Manfrin M. Hospital discharge planning for frail older people and their family. Are we delivering best practice? A review of the evidence. J Clin Nurs. 2009;18:2539-2546.

14. Romøren TI, Torjesen DO, Landmark B. Promoting coordination in Norwegian health care. Int J Integr Care. 2011;11:1-8.

15. Samhandlingsreformen. Rett behandling - på rett sted - til rett tid [The Coordination Reform. Proper Treatment - At the Right Place at the Right Time]. Report number 47 to the Storting (2008-2009). Oslo, Norway: Ministry of Health and Care Services. Norwegian. Available from: http://www.regjeringen.no/pages/2206374/PDFS/ STM200820090047000DDDPDFS.pdf. Accessed November 20, 2014.

16. Grimsmo A. Hvordan har kommunene løst utfordringen med utskrivingsklare pasienter? [What happens when municipalities are charged for patients waiting in hospitals for proper primary care to be established?]. Sykepleien Forskning. 2013;2(8):148-155. Norwegian.

17. Norwegian Directorate of Health. Samhandlingsstatistikk 2013-2014 [Statistics of Cooperation 2013-2014] (Report IS-2245). Olso, Norway: Helsedirektoratet $\mathrm{v} /$ Trykksaksekspedisjonen; 2015. Norwegian Available from: https://helsedirektoratet.no/Lists/Publikasjoner/ Attachments/798/Samhandlingsstatistikk-2013-2014-IS-2245.pdf. Accessed October 2, 2015.

18. Gautun H, Syse A. The Coordination Reform. How prepared are the municipalities to give services to the increasing number of patients from the hospitals? (NOVA report 8/2013). Oslo, Norway: Norwegian Social Research. Norwegian. Available from: http://www.hioa.no/Om-HiOA/ Senter-for-velferds-og-arbeidslivsforskning/NOVA/Publikasjonar/ Rapporter/2013/Samhandlingsreformen. Accessed October 2, 2015.

19. Hvalvik S, Ase Reierson I. Transition from self-supported to supported living: older peoples' experiences. Int J Qual Stud Health Well-being. 2011;6(4):1-9.

20. Lundman B, Aléx L, Jonsén E, et al. Inner strength in relation to functional status, disease, living arrangements, and social relationships among people aged 85 years and older. Geriatr Nurs. 2012;33(3): 167-175.

21. Bobay KL, Jerofke TA, Weiss ME, Yakusheva O. Age-related differences in perception of quality of discharge teaching and readiness for hospital discharge. Geriatr Nurs. 2010;31(3):178-187.

22. Allen J, Ottman G, Roberts G. Multi-professional communication for older people in transitional care: a review of the literature. Int J Older People Nurs. 2013;8(4):253-269.

23. Holland DE, Mistiaen P, Bowles KH. Problems and unmet needs of patients discharged "home to self-care." Prof Case Manag. 2011;16(5): 240-250.

24. Graneheim UH, Lundman B. Qualitative content analysis in nursing research: concepts, procedures and measures to achieve trustworthiness. Nurse Educ Today. 2004;24(2):105-112.

25. Bångsbo A, Dunér A, Lidén E. Patient participation in discharge planning conference. Int J Integr Care. 2014;14:e030.

26. Efraimsson E, Sandman PO, Hydén LC, Rasmussen B. Discharge planning: "fooling ourselves?" - patient participation in conferences. J Clin Nurs. 2004;13:562-570.

27. Swinkels A, Mitchell T. Delayed transfer from hospital to community settings: the older person's perspective. Health Soc Care Community. 2008;17(1):45-53.

28. Bastiaens H, Van Royen P, Pavlic DR, Raposo V, Baker R. Older people's preferences for involvement in their own care: a qualitative study in primary health care in 11 European countries. Patient Educ Couns. 2007;68(1):33-42.

29. Belcher VN, Fried TR, Agostini JV, Tinetti ME. Views of older adults on patient participation in medication-related decision making. $J$ Gen Intern Med. 2006;21(4):298-303.
30. Funk LM. Who wants to be involved? Decision-making preferences among residents of long-term care facilities. Can J Aging. 2004;23(1):47-58.

31. Bridges J, Flatley M, Meyer J. Older people's and relatives' experiences in acute care settings: Systematic review and synthesis of qualitative studies. Int J Nurs Stud. 2010;47(1):89-107.

32. Bynum JP, Barre L, Reed C, Passow H. Participation of very old adults in health care decisions. Med Decis Making. 2014;34(2):216-230.

33. Foss C, Hofoss D. Elderly persons' experiences of participation in hospital discharge process. Patient Educ Couns. 2011;85:68-73.

34. Foss C. Elders and patient participation revisited - a discourse analytic approach to older persons' reflections on patient participation. $J$ Clin Nurs. 2011;20(13-14):2014-2022.

35. Gitlin LN, Wolff J. Family involvement in care transitions of older adults. What do we know and where do we go from here? Ann Rev Gerontol Geriatr. 2011;31(1):31-64.

36. Roberts K. Exploring participation: older people on discharge from hospital. $J A d v$ Nurs. 2002;40:413-420.

37. Horwitz LI, Moriarty JP, Chen C, et al. Quality of discharge practices and patient understanding at an academic medical center. JAMA Intern Med. 2013;173:1715-1722.

38. Rose JH, Bowman KF, Kresevic D. Nurse versus family caregiver perspectives on hospitalized older patients: an exploratory study of agreement at admission and discharge. Health Commun. 2009;12(1): 63-80.

39. Toles M, Abbott K, Hirschman K, Naylor M. Transitions in care among older adults receiving long-term services and supports. J Gerontol Nurs. 2012;38:40-47.

40. Huby G, Brook JH, Thompson A, Tierny A. Capturing the concealed: interprofessional practice and older patients' participation in decisionmaking about discharge after acute hospitalization. $J$ Interprof Care. 2007;21(1):55-67.

41. Knight DA, Thompson D, Mathie E, Dickinson A. "Seamless care? Just a list would have helped!" Older people and their carer's experiences of support with medication on discharge home from hospital. Health Expect. 2011;16(3):277-291.

42. Laugaland K, Aase K, Barach P. Interventions to improve patient safety in transitional care: a review of the evidence. Work. 2012; 41(Suppl 1):2915-2924.

43. van Walraven C, Taljaard M, Bell C, et al. A prospective cohort study found that provider and information continuity was low after patient discharge from hospital. J Clin Epidemiol. 2010;63(9):1000-1010.

44. Kydd A. The patient experience of being a delayed discharge. J Nurs Manag. 2008;16(2):121-126.

45. De Marchis GM, Foderaro G, Jemora J, et al. Mild cognitive impairment in medical inpatients: the Mini-Mental State Examination is a promising screening tool. Dement Geriatr Cogn Disord. 2010;29(3):259-264.

46. Berglund H, Wilhelmson K, Blomberg S, Duner A, Kjellgren K, Hasson H. Older people's views of quality of care: a randomized controlled study of continuum of care. J Clin Nurs. 2013;22(19-20):2934-2944.

47. Altfeld S, Shier G, Rooney M, et al. Effects of an enhanced discharge planning intervention for hospitalized older adults: a randomized trial. Gerontologist. 2013;53(3):430-440.

48. Tung YC, Cooke M, Moyle W. Sources older people draw on to nurture, strengthen and improve self-efficacy in managing home rehabilitation following orthopedic surgery. J Clin Nurs. 2013;22(9-10):1217-1225.

49. Statistics Norway. Hvor lenge kommer vi til å leve? Levealder og aldersmønster for dødeligheten i Norge, 1900-2060 [How long are we going to live? Life Expectancy and Living Conditions in Norway, 1900-2060]; 2005. Norwegian. Available from: http://www.ssb.no/a/ publikasjoner/pdf/oa_200506/folkfram05.pdf. Accessed November 20, 2014. 


\section{Supplementary material I \\ Interview guide \\ Introduction}

- How are you feeling today?

\section{The patient's experiences of treatment and care}

- Why were you admitted to hospital?

- Can you explain how you experienced being patient in the hospital?

- Can you describe in what way you participated in planning the transfer from hospital and home/to nursing home?

- How would you describe the process of being transferred from hospital to home/nursing home?

- How did you experience the first period of being at home/ in nursing home?

\section{Publish your work in this journal}

Patient Preference and Adherence is an international, peer-reviewed, open access journal that focuses on the growing importance of patient preference and adherence throughout the therapeutic continuum. Patient satisfaction, acceptability, quality of life, compliance, persistence and their role in developing new therapeutic modalities and compounds to optimize clinical outcomes for existing disease states are major areas of interest for the journal. This journal has been accepted for indexing on PubMed Central. The manuscript management system is completely online and includes a very quick and fair peer-review system, which is all easy to use. Visit http://www. dovepress.com/testimonials.php to read real quotes from published authors.

\footnotetext{
Submit your manuscript here: http://www.dovepress.com/patient-preference-and-adherence-journal
} 